\title{
The Mechanical Behaviour of Eggshell and Coconut Coir Reinforced Composites
}

\author{
B. Sudharsan ${ }^{1} \quad$ Dr.S.Sunil Kumar Reddy ${ }^{2}$ M.Lava Kumar ${ }^{3}$ \\ 1. M,Tech scholar, Siddarth Institute of Engineering and Technology, Putttur, A.P \\ 2. Professor, Siddarth Institute of Engineering and Technology, Puttur, A.P \\ 3. Assistant Professor, Siddarth Institute of Engineering and Technology, Putttur, A.P
}

\begin{abstract}
In present days, automobile industries are rapidly increased. All the automobile industries are in the process of supplying the vehicles at low cost. The major cost of the automobile components is its body parts. As per the European Union and Asian countries automotive components end life is very important factor in the design of the automotive. So everybody is concentrating on new materials which will be strong enough, less weight, recyclable with reduced cost. Hence all the researchers are concentrated on the composite materials which have all the above properties. Generally the composite materials are synthetic and natural. In that natural fibre is ahead of synthetic with their low cost, low density, stiffness, fairly mechanical properties, high specific strength, non-abrasive, ecofriendly and biodegradable characteristics. In our country much amount of coconut coir fibre is obtainable which have good tensile strength. Similarly large amount of egg shells are also on hand as wastage from food industries which normally produces pollution. But this egg shells are having good compressive strength. Hence the present work is concentrated on coconut coir fibres and egg shell composites. The strength of the composites depends on the compositions of the ingredients. So to obtain new composite materials different proportions of coconut coir and egg shell powder is added and the mechanical properties of all the components are tested and the same is represented.
\end{abstract}

Key words: Coconut coir fiber, eggshell powder, epoxy hardener and resin.

\section{INTRODUCTION}

Different components of an automobile need dissimilar properties based on their usage. For obtaining good performance of automobile, the components should be low weight, high strength with biodegradable characteristics. But the conventional metal alloy does not have these properties. So much amount of research work is concentrated on composite materials. The composite materials have good strength, resistance to extreme temperatures and wear in industries. This composite was used in aerospace, transport, packing and sports. In fiber reinforced polymer matrix (FRP), the matrix either thermo plastic or thermo settings. Majorly used thermo plastics are PVC (poly vinyl chloride) and thermo setting resins are epoxy. Now a day`s epoxy resins are widely used because they have high adhesive properties. The composite materials are nothing but combination of two or more than two materials distinct phases to increase the strength of particular material. In composite material, the fiber is reinforced the matrix to increase the strength of matrix. The matrix material supports the reinforced material by maintaining their relative position. The reinforced materials impart special mechanical and physical properties to the matrix material.

In composite materials, fiber (reinforcement material) plays major role because they have higher volume and high strength transformation. Hence it is concluded that the capacity of fiber relays on the strength and other properties of the composites. The fiber selection for a particular application is based on fiber density, strength, carbon percentage and cost. The synthetic or conventional fiber has large cost. So much amount of concentration is done on natural fiber. Mostly used natural fibers are jute, coconut coir, sisal, hemp.

P.Shashi shankar et al. [3] reported that flax fiber content from $10-30 \%$ by mass was mixed with high density polyethylene (HDPE) by extrusion and injection moulding to produce composites. The results showed that increasing fiber content increases the mechanical properties up to $20 \%$ by volume and then it dropped. Mueller N.M. White et al [16] has represented that in U.S alone 150,000tons of this material is disposed in landfills. The eggshell contains $95 \%$ calsium carbonate in the form of calcite and $5 \%$ organic 
materials as type $X$ collagen, sulphated polysaccharides and other proteins. According to Avatar singh saroya ${ }^{4}$ et al [5] addition of eggshell to polymer leads to decrease in the tensile strength and modulus of elasticity and shore D-hardness and other hands increases the \%of elongation at break and impact strength. Water absorption capacity of composite also increased. So, with the addition of eggshell powder to coconut coir powder the compression and impact strength of composites increases.

\section{MATERIALS AND METHODS}

For the preparation of composite material, the coconut coir fiber and eggshell powder are considered as reinforced material and epoxy as hardener resin. Further these composites are tested for mechanical properties. The total work consists of

\section{Preparation of composite materials}

2. Testing of composite materials

\section{Preparation of Composite Materials}

1. In this, coconut coir fiber is considered as reinforce material and epoxy act as resin to fiber. The mechanical behaviour of composite is based on fiber percentage. With the variation of fiber contain the strength of composite is varied.

2. Next, different size of dies is prepared for variable composites for different tests. For the compression test very thick mild steel plates are welded at each ends of the plates to join the cube mould cavity of size $40 \mathrm{~mm}$. For tensile test, PVC pipes of internal diameter of $1.6 \mathrm{~cm}$ is considered and cut at middle through the length of pipe for composite material filling and removing. For impact test take $3 \mathrm{MS}$ plates and weld through the length to provide rectangular mould cavity and further the composite is filled in the pipe.

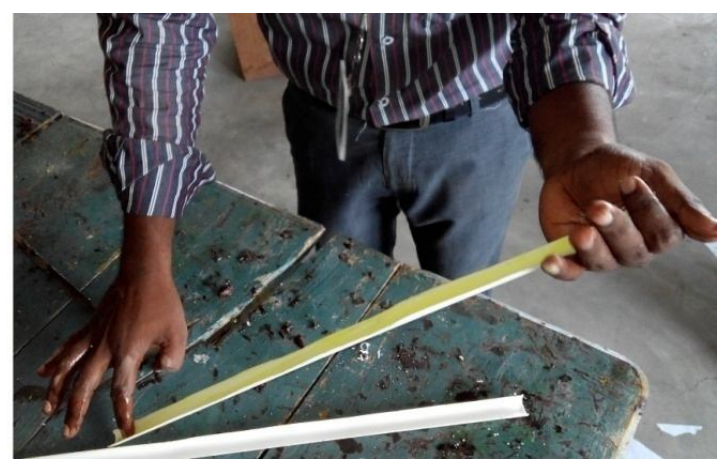

Fig 1 The Dies for Prepare Composite Materials

3. The coconut coir is further cleaned by removing the waste from coir by hand layup method and dried in the sunlight for about 12 hours. After the drying process, the coir fibre is powdered with grinding machines and filtered to uniform grain size of 150 microns.

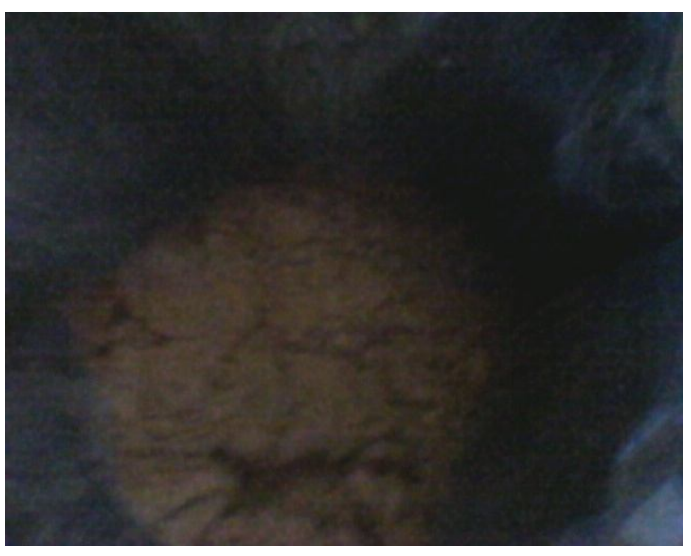

Fig 2 Preparation of Coconut Coir Fiber

4. Similarly, the eggshells are collected from food industries. Further the egg shells are cleaned by removing the inside layers of eggshells. After cleaning immerse them into $\mathrm{NaOH}$ solution in 2 hours to remove bacteria. Further, the egg shells are dried in sunlight for about 12 hours. The clean and dry eggshells are powered by grinding machines and prepared to uniform grain size of 150 micros by using test sieves. 


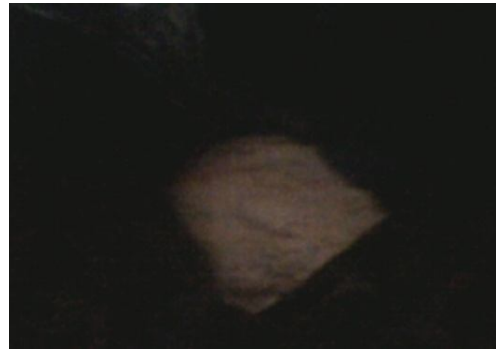

Fig 3 Preparation of Eggshell Powder

5. further the composite is prepared by taking, the coir fiber powder and eggshell powder at different ratios and add epoxy hardener to prepare good mixture at room temperature.

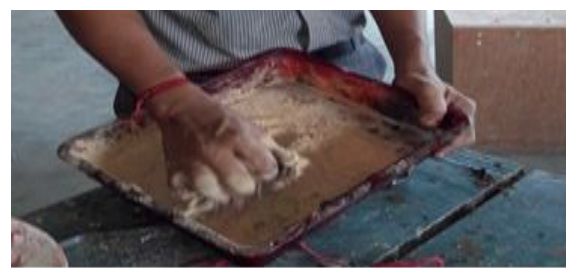

Fig 4 Mixing of Powders with Epoxy at Different Ratios

6. The wet composite material mixture was inserted into compression, tensile and impact test dies at related ratios of mixtures. The composite material inside the die is made to dry inside the room for 24hours.

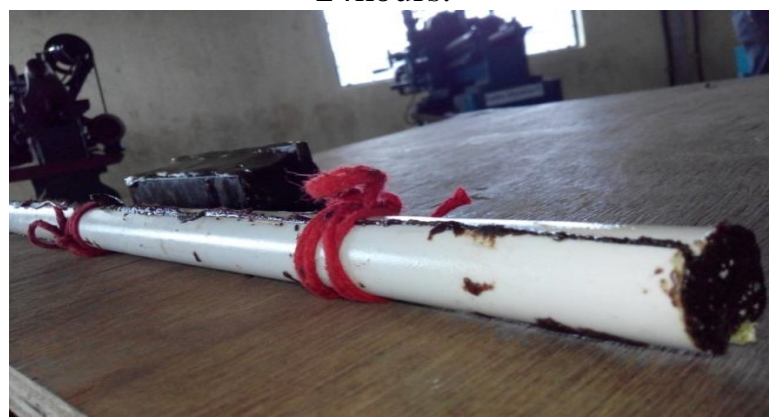

Fig 5 The Composite Materials inside the Related Dies

7. After drying, the composite material is removed from the dies; cut and finish the composite material into pieces as per ASTM Standards.

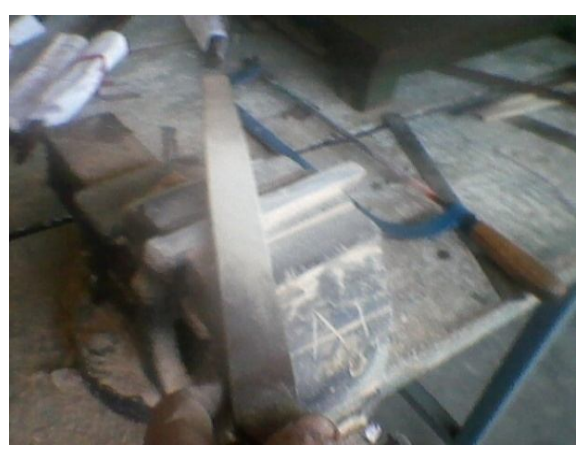

Fig 6 cutting and finishing of specimens

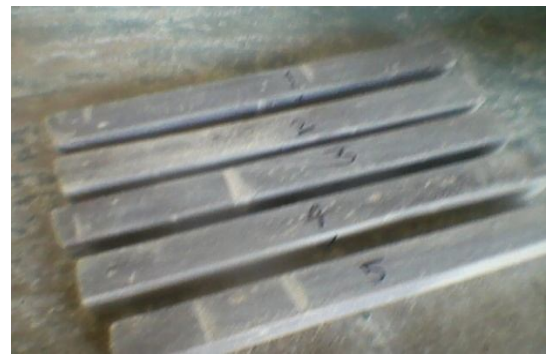

Fig 7 The Composite Materials for as Per ASTM Standards Differen tRatios of Powders

\section{Testing of Composite Materials}

The hand layup composite material pieces was tested by the testing machines and observed the mechanical behaviour of composites in different tests. The universal testing machine was used for ultimate tensile strength, compression testing machine was used for ultimate compression strength and Impact testing machine was used for impact test. The testing process is as follows.

In this testing process the load is applied on specimen and the reading of load at which the specimen was beaked is noted. 


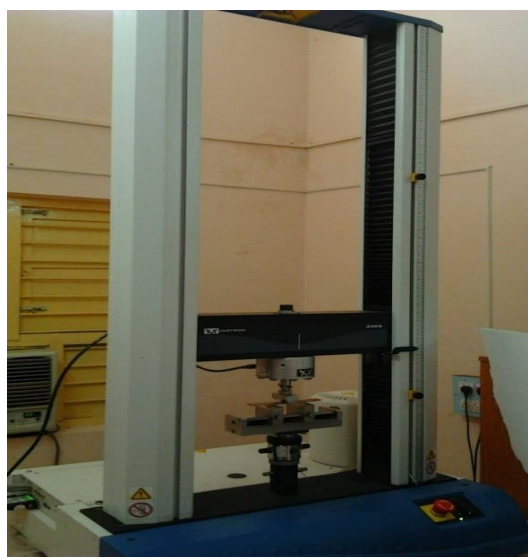

Fig 8 Testing of Composite Materials

\section{RESULTS AND DISCUSSION}

The composites are prepared with different ratios of coconut coir powder \& egg shell powder and are further tested for different mechanical properties and are represented as below.

\section{Tensile Test Properties}

The tensile strength of the composite depends on the quantity and quality of fiber used. The below Graph 1 exhibits the variation of tensile strength with different composite ratios for the maximum peak loads. The ratio $\mathrm{C} 1$ has largest tensile stress of $64.69 \mathrm{~N} / \mathrm{mm}^{2}$ and C5 has lowest tensile strength of $29.86 \mathrm{~N} / \mathrm{mm}^{2}$. The tensile strength of composite is uniformly decreasing from $\mathrm{C} 1$ to $\mathrm{C} 5$. It is evident that with the increase of coconut coir percentage, the tensile strength of the composite is gradually increases. This is because of surface and chemical modification which improve the adhesive property between the two materials. This further made the better dispersion of fiber and interaction between them. Therefore it indicates that the chemical treatment of the fiber significantly increases the bonding strength and further tensile strength.

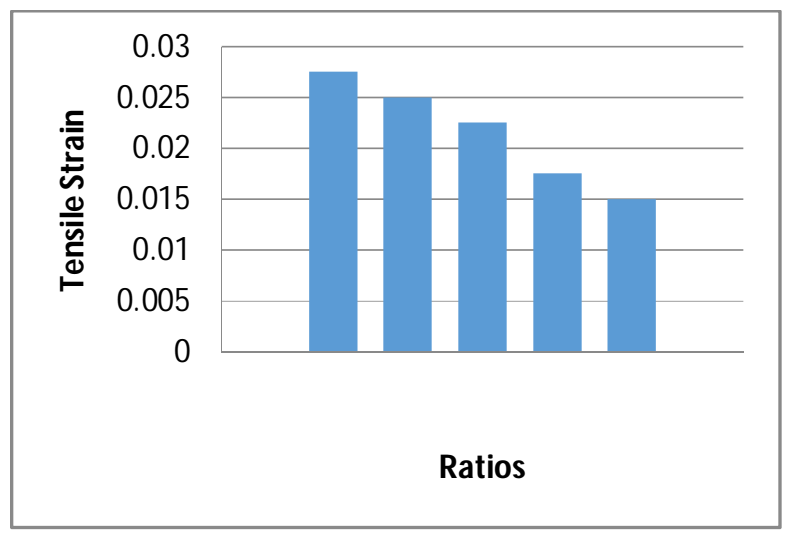

Fig 9 Variation of Tensile Strain Material for Different Mixtures of Composite

Compression Test Properties

The compression strength of the composite mainly depends on the type of natural fibre content used and increases with the amount of fibre content. The compressive strength variation with the percentage of composite material is illustrated in the above graph 6. It is evident from the graph that the composite material $\mathrm{C5}$ is having more compressive strength.

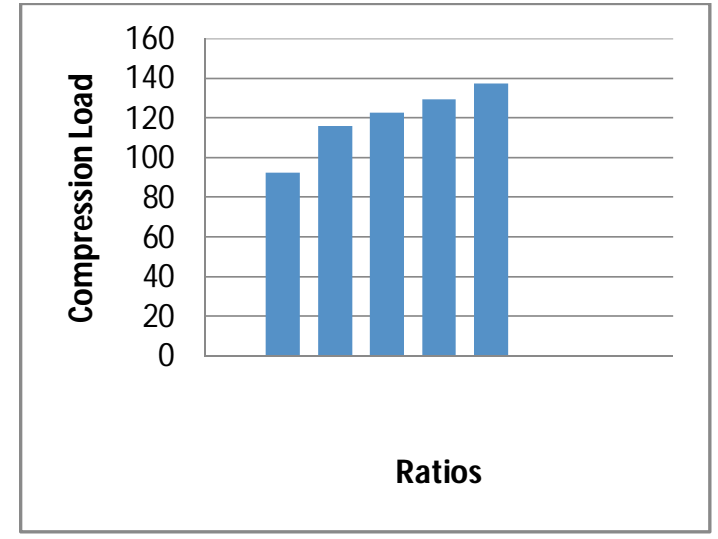

Fig 10 Variation of Compression Strength for Different Mixtures of Composite Material

As the egg shell powder content is increasing the composites compressive strength will also increase. It is observed from the graph that the material C5 shows maximum compressive strength of $137.5 \mathrm{KN}$. All other composites strength is in between $\mathrm{C} 1$ to $\mathrm{C} 5$. The treatment of the fibre modified the surface energy and the tension of the 
fiber and further improves the molecular chain reaction.

\section{CONCLUSIONS}

The mechanical behaviour of the $\mathrm{CE}$ composite material has been estimated in the present work. The materials of CE composite had taken in different ratios are mixed with resin and hardener and made into geometrical shapes. These have been tested experimentally for impact, compression and tensile tests. The results reveal that high compression strength is obtained for C5 composition, because eggshell has good compressive strength. For tensile test C1 composition has good tensile strength and strain, because coconut coir fiber has good tensile properties. In the $\mathrm{C} 1$ composition the coconut coir percentage is more than egg shell powder. So from the present work it is concluded that the tensile strength of composite depend on coir fiber and compression strength of composite depend on eggshell quantity.

\section{REFERENCES}

[1] Journal of Reinforced Plastics and Composites 2010 29: 2387 originally published online 24 May 2010

[2] Banana Fiber Reinforced Polymer Composites - A Review ${ }^{1}$

[3] P.Shashi Shankar ${ }^{2}$, Dr.K.Thirupathi Reddy and V.Chandra Sekhar, Mechanical Performance and Analysis of Banana Fiber Reinforced Epoxy Composites (IJRTME) Vol. 1, issue. 4, Nov. 2013

[4] K. Van de Velde and P. Kiekens: Thermal degradation of flax: The determination of kinetic parameters with thermogravimetric analysis, Journal of Applied Polymer Science, Vol. 83, No. 12, pp. 2634-2643, 2002

[5] Avatar singh saroya ${ }^{4}$, Study of mechanical properties of hybrid natural fiber composite

[6] Xun Lu ${ }^{7}$ Ming Qiu Zhang2, The Preparation of Self-Reinforced Sisal Fiber Composites

[7] Mueller D.H and Krobjilowski A, "New Discovery in the Properties of Composites Reinforced with Natural Fibers", Journal of Industrial Textiles, 33(2), 2003, pp.111-129.

[8] Brändström J, "Micro and ultrastructural aspects of Norway spruce tracheids: a review", IAWA Journal, 22 (4), 2001, pp. 333-353.

[9] Mahzan, S., Zaidi, A.M., Ahmad, Arsat N., Hatta, M.N.M, Ghazali, M.I, Study on sound absorption properties of coconut coir fibre composite with added recycled rubber, Inter. J. of integ. engg., 2(1) (2010) 29-34

[10] S.C. Mishra, Nadiya Bihari Nayak and Alok Satapathy: Investigation on Bio-waste Reinforced Epoxy Composites, Journal of Reinforced Plastics \& Composites, Vol. 29, No. 19, pp. 3016-3020, 1999.

[11] Jeffrey W. Kock: Physical and Mechanical Properties of Chicken Feather Materials, A thesis presented to the academic faculty Georgia Institute of Technology, 2000.

[12] N.M. White, M.P. Ansell: Straw reinforced polyester composites, Journal of Materials Science, Vol. 18, No. 5, pp. 1549-1556, 1993.

[13] W. Wasylciw: The utilization of industrial hemp stalks in composite panels, in: Proceedings of the Meeting of the Eastern Canadian Section of the Forest Products Society ., Winnipeg, Manitoba, 1999, pp. $45-48$.
[14] Tran, N.-H., Ogihara, S., Kobayashi, S., M echanical Properties Of Short Coir/Pbs Biodegradable Composites: Effect Of Alkali Treatment And Fiber Content, 18th International Conference On Composite M aterials. 22. 